\title{
Microstructural Features and Wear Characteristics of Semi-Solid Processed A356 Aluminum Alloy
}

\author{
K. Raju ${ }^{1, *}$, N. Gopi Krishna², L. Sankara Rao², and S. N.Ojha ${ }^{2}$ \\ ${ }^{1}$ Department of Mechanical Engineering, St. Joseph Engineering College (VTU), Mangaluru - 575028 \\ ${ }^{2}$ Department of Metallurgical Engineering, Indian Institute of Technology (BHU), Varanasi - 221005
}

\begin{abstract}
In the present study the microstructural features and tribological characteristics of hot forged A356 Al alloy subjected to SIMA (Strain induced melt activation) and T6 heat treatment (semi-solid) processes have been investigated. The SIMA process consists of hot forging of alloy at $325^{\circ} \mathrm{C}$ followed by cold forging at room temperature, isothermal holding at $580^{\circ} \mathrm{C}$ for $10 \mathrm{~min}$ and quenching. In case of T6 heat treatment, the hot forged alloy was solution treated at $540^{\circ} \mathrm{C}$ for 4 hours followed by quenching in cold water and artificial aging at $155^{\circ} \mathrm{C}$ for 3 hours. The microstructure of the alloy exhibited a spherical or globular morphology of the primary a-phase with uniform distribution of solutes in the interdendritic region. A detailed analysis of the solidification behaviour of the melt from semi-solid region of the alloy is reported. The reasons for the consequential changes in tribological properties of A356 Al alloy processed by SIMA andT 6 heat treatment have been clearly brought out.
\end{abstract}

Keywords: A356 Al alloy, SIMA process, Microstructure, Hardness, Wear.

\section{INTRODUCTION}

Semi solid processing is an effective near net shape forming process involving treatment of metals or alloys in a semi solid state for transforming the dendritic morphology as observed in as-cast alloys in to globular or non dendritic form resulting in improved mechanical and tribological properties of the alloys. Though it is possible to produce globular morphology by conventional casting, it takes a very long time but semi solid processing is fast and efficient [1-5]. The main requirement for semi solid forming is that the alloys should have an equiaxed morphology free of dendrites [6]. Suitable processes have been proposed for providing required morphologies for semi solid forming of aluminum (Al) alloys [7, 8]. Amongst them SIMA (strain induced melt activation) process is an appropriate technique being widely used for Al alloys as it is simple and a low cost process [9-11]. It involves hot forging of the alloy followed by cold forging at room temperature, isothermal holding and quenching resulting in globular morphology of primary $\alpha$-phase with uniform distribution of solutes in the interdendritic region [12]. Al alloys with $\mathrm{Si}$ find applications in automotive and aerospace industries due to their high strength to weight ratio, low thermal expansion coefficient and better wear and corrosion resistance [13]. A356 alloy is one such Al alloy having $7 \% \mathrm{Si}$ and $0.35 \% \mathrm{Mg}$. Considerable amount of work has been carriedout on A356 Al alloy by SIMA process for

*Address correspondence to this author at the Department of Mechanical Engineering, St. Joseph Engineering College (VTU), Mangaluru - 575 028;

Tel: +91- 8123798293; E-mail: rajuksjec@rediffmail.com improving its wear and mechanical properties. Apart from SIMA process, T6 heat treatment that consists of hot forging of alloy followed by solution treatment, quenching and artificial aging is also used for improving the wear and mechanical properties of Al-Si alloys. Wang et al. have worked on super heat processing of thixoforged A356 Al alloy and reported that T6 heat treatment has improved the tensile properties of the alloy as compared to that of as-cast alloy [14]. Kilicli et al. have reported that AA7075 alloy prepared by thixocasting + T6 process has better mechanical properties than that of thixocast alloy [15]. Yu et al. have worked on A356 Al alloy processed by magneto hydrodynamic stirring + T6 heat treatment and reported that T6 heat treatment has improved the tensile strength and elongation of the alloy to a greater extent [16]. However there is no report found in the literature on the comparative study conducted on mechanical and wear properties of Al alloys by SIMA and T6 heat treatment processes. Hence an attempt is made in this study to compare the tribological properties of A356 Al alloy by SIMA and T6 heat treatment processes.

\section{EXPERIMENTAL DETAILS}

\subsection{Materials Processing}

The as-cast $\mathrm{A} 356 \mathrm{Al}$ alloy (Al-7Si-0.35Mg alloy) has been remelted to $750^{\circ} \mathrm{C}$ in a pit furnace and poured in to a copper mould of $30 \times 30 \times 150 \mathrm{~mm}^{3} . \mathrm{C}_{2} \mathrm{Cl}_{6}$ has been added to degasify the gases present in the melt if any. Three types of samples namely hot forged, hot forged + T6 heat treated and SIMA processed were prepared. The samples size was $25 \times 25 \times 45 \mathrm{~mm}^{3}$. Hot 
forging is done in a power hammer at a temperature of $325^{\circ} \mathrm{C}$ for reducing the thickness by $30 \%$. Cold forging is done at room temperature prior to SIMA process for reducing the thickness further by $20 \%$. T6 heat treatment of hot forged samples was done in three steps by solutionizing the samples at $540^{\circ} \mathrm{C}$ for 4 hours in a furnace followed by quenching in cold water and artificial aging at $155^{\circ} \mathrm{C}$ for 3 hours.

\subsection{Materials Testing}

Microstructural features were explored under an optical microscope. The samples were polished using standard polishing techniques and etched by Keller's reagent ( $1 \mathrm{vol} \% \mathrm{HF}, 1.5 \mathrm{vol} \% \mathrm{HCl}, 2.5$ vol $\% \mathrm{HNO}_{3}$, and rest water). Wear tests were conducted on a pin on disc wear testing machine for sliding distances of 400 , 800,1200 and $1600 \mathrm{~m}$ by varying the load from 20 to $50 \mathrm{~N}$ at a sliding speed of $1 \mathrm{~m} / \mathrm{s}$ for hot forged, hot forged + T6 heat treated and SIMA alloys and the wornout surfaces of the wear samples were examined under SEM. Vickers hardness testing has been carriedout for evaluating the bulk hardness of the samples.
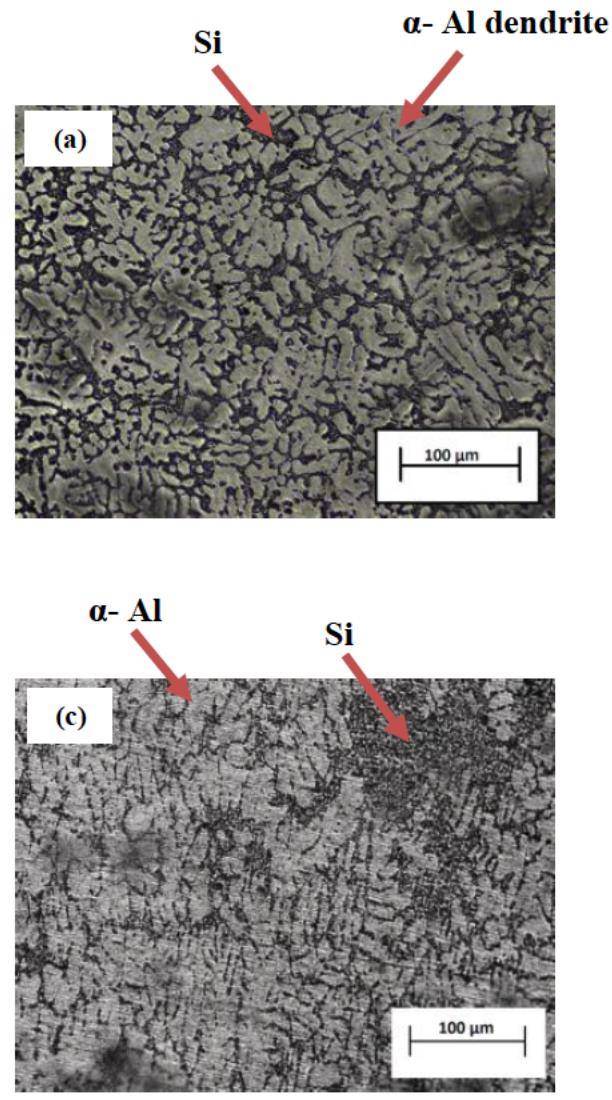

\section{RESULTS AND DISCUSSION}

\subsection{Microstructural Features}

The microstructures of A356 Al alloy processed by different routes are shown in Figure 1 . The microstructure of as-cast alloy is shown in Figure 1(a). It consists of dendrites of $\alpha-\mathrm{Al}$ and needle shaped eutectic $\mathrm{Si}$. The same was reported by Hassas et al., Chitra et al., and Haghdadi et al. [17-19]. The microstructure of hot forged alloy is shown in Figure $\mathbf{1}(\mathbf{b})$. It consists of white and grey regions. It is clearly evident from the microstructure that the dendrites have been broken and the grains have been elongated due to deformation [18]. The microstructure of hot forged and T6 heat treated alloy is shown in Figure 1(c). From the microstructure it is evident that spherical particles are observed at the grain boundaries. During solution heat treatment the solute elements like $\mathrm{Mg}$ and $\mathrm{Si}$ form a super saturated solid solution in primary $\mathrm{Al}$ to enable the formation of strengthening precipitate like $\mathrm{Mg}_{2} \mathrm{Si}$ during artificial aging and the remaining $\mathrm{Si}$ will be spheroidized in A356 Al alloy. The microstructure of SIMA (hot and cold forged) alloy is shown in Figure $\mathbf{1}(\mathbf{d})$. It consists of globular morphology. When the alloy
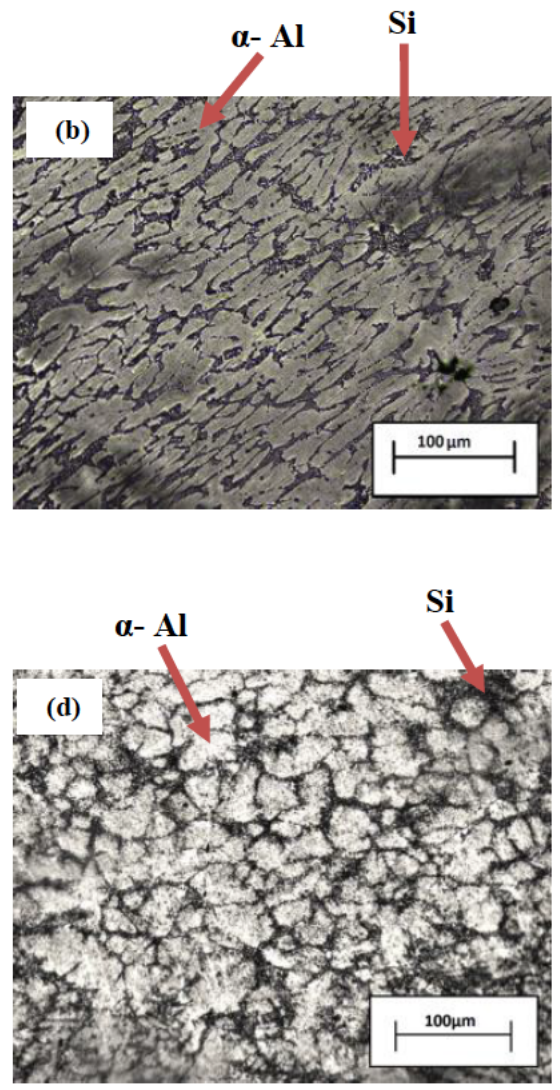

Figure 1: Microstructures of A356 Al alloy (a) as-cast alloy (b) Hot forged alloy (c) Hot forged + T6 heat treated alloy (d) SIMA processed alloy. 
is subjected to deformation, the dendrites will be broken down to smaller fragments. The more the deformation, the more wil be the kinetics of spheroidization as the deformation induces defects like vacancies, dislocations which enhances the atomic diffusion of solute atoms like Mg and Si [19, 20]. Wang also has reported the same in his work that after the T6 heat treatment the remaining $\mathrm{Si}$ will be transformed to globular shape in the alloy [14]. Peng et al. have also worked on T6 heat treated A356 Al alloy and reported that the aspect ratio of $\mathrm{Si}$ present in the original alloy reduces and spheroidization of Si particles takesplace resulting in better mechanical properties of the alloy [21].

\subsection{Variation in Bulk Hardness}

The bulk hardness values of as-cast, hot forged, hot forged $+\mathrm{T} 6$ heat treated and SIMA processed A356 Al alloys are 60, 66, 77 and $86 \mathrm{VHN}$ respectively. The low hardness of as-cast alloy is due to the dendritic structure that acts as a stress raiser during loading. Hot forged alloy has better hardness than as-cast alloy. This may be due to the introduction of dislocations by hot forging that hardens the alloy. The hardness of hot forged and T6 heat treated alloy is better than that of as-cast and hot forged alloys. This may due to the formation of $\mathrm{Mg}_{2} \mathrm{Si}$ precipitate and spheroidization of $\mathrm{Si}$. The hardness of SIMA processed alloy was the highest among the other alloys. This may be due to the globular shaped grain structure. Hardness value depends on indentation on the surface and indentation deforms the alloy. For deformation to occur dislocations should move at grain boundaries and dislocations have to change their orientation and direction. The more the grain boundaries, the more will be the change in dislocations orientation and direction and this makes deformation difficult and less. Microstructure with globular morphology has a large grain boundary area than any other morphology. Because of this globular morphology, SIMA alloy has the highest hardness.

\subsection{Wear Characteristics}

The wear characteristics of A356 Al alloy processed by different routes are shown in Figure 2. In Figure 2 (a) - (c) it has been observed that at low loads and low sliding distance the difference in weight loss among the alloys is very marginal. As the load increases the difference in weight loss increases and at higher load a remarkable increase in the weight loss has been observed. This is due to the seizure where melting occurs and a considerabe amount of material will be lost. This phenomenon has been observed in all the alloys at higher load and longer sliding distance. In Figure $\mathbf{2}$ (d) it can be clearly seen that SIMA alloy has the lowest wear rate compared to hot forged and hot forged + T6 heat treated alloys. Also it shows that hot forged + T6 heat treated alloy has better wear resistance than hot forged alloy. This may be due to the microstructural changes occuring due to the T6 process in which silicon is spheroidized and elongated grains have been slightly transformed to globular shape.
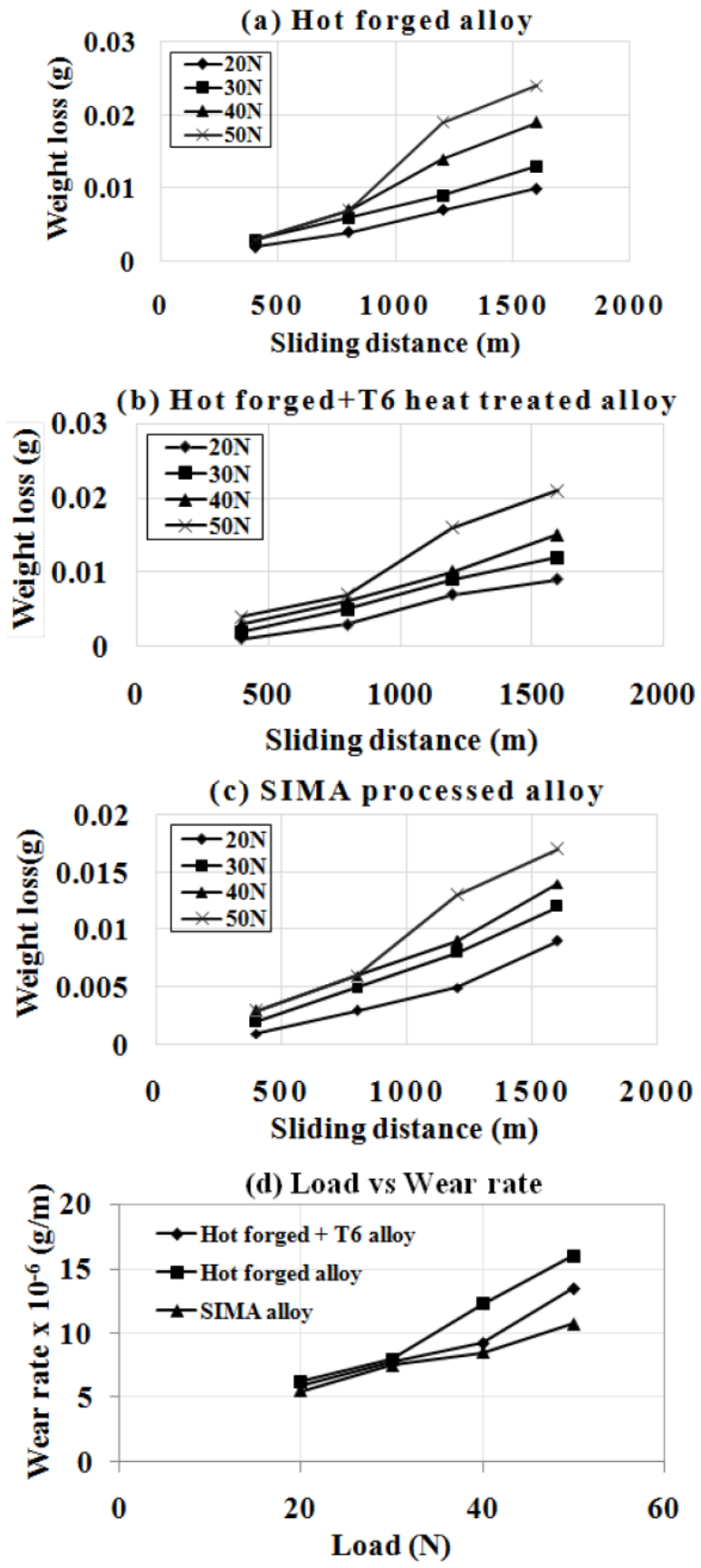

Figure 2: Weight loss vs sliding distance graphs of A356 Al alloy (a) Hot forged alloy (b) Hot forged + T6 heat treated alloy (c) SIMA processed alloy (d) Wear rate vs load graph of A356 Al alloys. 


\subsection{Morphology of Wornout Surfaces}

The wornout surfaces of hot forged, hot forged+T6 heat treated and SIMA processed A356 Al alloys are shown in Figure 3. In case of hot forged alloy shown in Figure 3(a) continuous lines are observed indicating abrasion wear and deep grooves are the result of abrasion. Generally the hard steel particles present on the disc scratch the surface and plough the material forming deep grooves. If the material is soft then the ploughing action would be severe forming abrasion grooves. Incase of hot forged + T6 heat treated alloy as shown in Figure $\mathbf{3}(\mathbf{b})$ a small amount of debris particles are observed but not as much as seen in SIMA processed alloy. In case of SIMA processed alloy shown in Figure 3(c) it is clearly seen that in addition to continuous lines most of the part is smooth indicatng adhesion wear and the tracks on the surface are not deep and are wide indicating a high wear resistance. Also it has shown the presence of debris particles on the surface proving it to be a hard material. This improvement in wear resistance has been attributed to the increase in hardness of the alloy [22]. Ultimately SIMA processed alloy shows better wear resistance

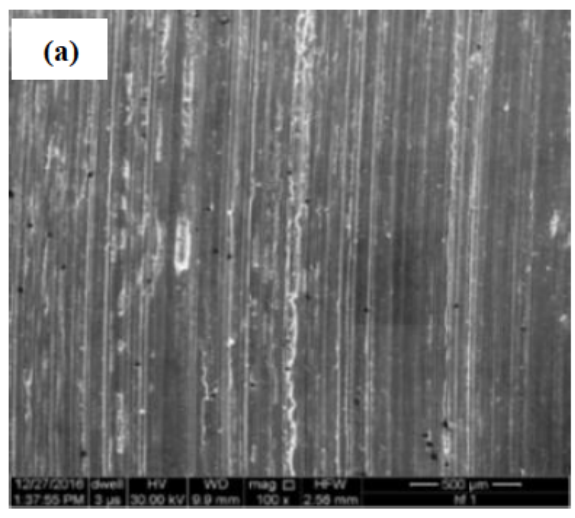

compared to other alloys, however T6 heat treatment also improved the wear resistance as compared to hot forged alloy. This is because of the fact that the wear resistance in this alloy mainly depends on the microstructural features like size, shape and amount of Si present in the material [22]. Here the Si has been transformed to globular form there by increasing the resistance to wear as compared to $\mathrm{Si}$ which is not spherical and having considerable aspect ratio due to which stress concentration develops making it easier for nucleation and propagation of the cracks.

\section{CONCLUSIONS}

The following conclusions may be drawn from the present study:

1. The microstructure of SIMA A356 Al alloy consists of globular morphology of primary $\alpha-A l$ with uniform distribution of solutes in the interdendritic region.

2. The SIMA alloy has the highest hardness compared to that of as-cast, hot forged and hot forged $+T 6$ heat treated alloys.

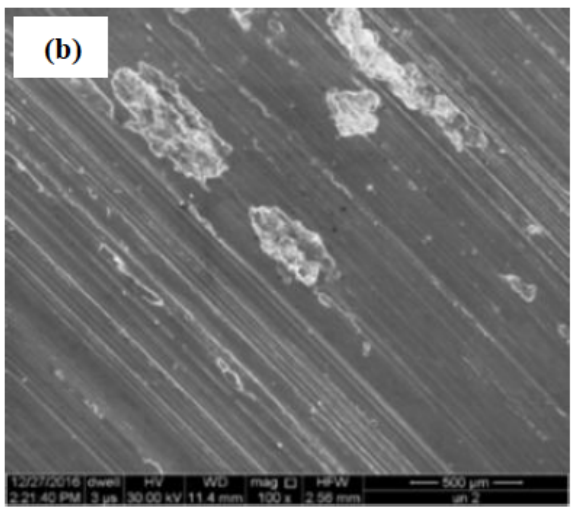

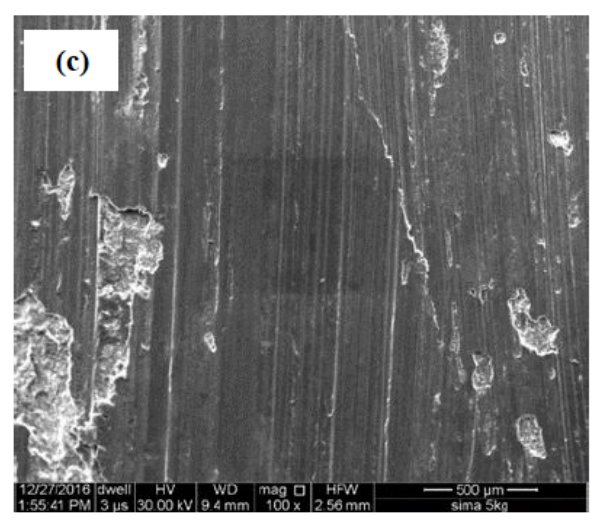

Figure 3: Worn out surfaces of A356 Al alloy (a) Hot forged alloy (b) Hot forged + T6 heat treated alloy (c) SIMA processed alloy. 
3. The wear resistance of SIMA alloy is invariably higher than that of hot forged and hot forged $+\mathrm{T} 6$ heat treated alloy.

4. The increase in hardness and wear resistance of SIMA alloy is due to globular morphology of primary $a-A l$ in the microstructure.

5. The debris particles have been observed on the worn out surfaces of SIMA alloy indicating that the alloy is hard.

\section{REFERENCES}

[1] Kapranos P, Kirkwood DH, Atkinson HV, et al. Journal of Materials Processing Technology 2003; 135: 271. https://doi.org/10.1016/S0924-0136(02)00857-9

[2] Wang JL, Su YH and Tsao CYA, Scripta Materialia 1997; 37 : 2003. https://doi.org/10.1016/S1359-6462(97)00394-1

[3] Chen TJ, Hao Y and Sun J, Materials Science \& Engineering A 2002; 337: 73. https://doi.org/10.1016/S0921-5093(02)00018-7

[4] Czerwinski F, and Zielinska-Lipiec A, Acta Materialia 2003; 51: 3319. https://doi.org/10.1016/S1359-6454(03)00163-0

[5] Jiang QC, Wang HY, Wang JG, et al. Materials Science \& Engineering A 2004; 381: 223. https://doi.org/10.1016/j.msea.2004.04.022

[6] Zoqui EJ, Paes $\mathrm{M}$, and Robert $\mathrm{MH}$, Journal of Materials Processing Technology 2004; 153-154: 300. https://doi.org/10.1016/j.jmatprotec.2004.04.068

[7] Haghayeghi R, Zoqui EJ, Halvaee A and Emamy M, Journal of Materials Processing Technology 2005; 169: 382. https://doi.org/10.1016/j.jmatprotec.2005.04.071

[8] Jiang JF and Luo SJ, Transactions of Non-ferrous Metal Society of China 2007; 17: 46. https://doi.org/10.1016/S1003-6326(07)60046-6
[9] Luo S, Tian W and Zhang G, Transactions of Non-ferrous Metal Society of China 2001; 11: 547.

[10] Tzimas E and Zavaliangos A, Materials Science \& Engineering A 2000; 289: 228. https://doi.org/10.1016/S0921-5093(00)00908-4

[11] Wang Z, Ji Z, Hu M and $\mathrm{Xu} \mathrm{H}$, Materials Characterization 2011; 62: 925. https://doi.org/10.1016/j.matchar.2011.07.003

[12] Zhang L, Liu YB, Cao ZY, Zhang YF and Zhang QQ, Journal of Materials Processing Technology 2009; 209: 792. https://doi.org/10.1016/j.jmatprotec.2008.02.046

[13] Chen G, Du Z and Cheng Y, Materials \& Design 2012; 35 : 774. https://doi.org/10.1016/j.matdes.2011.10.046

[14] Wang S, Zhou N, Qi W and Zheng K, Transactions of Nonferrous Metal Society of China 2014; 24: 2214. https://doi.org/10.1016/S1003-6326(14)63335-5

[15] Kilicli V, Akar N, Erdogan M and Kocatepe K, Transactions of Non-ferrous Metal Society of China 2016; 26: 1222. https://doi.org/10.1016/S1003-6326(16)64223-1

[16] Yu YB, Song PY, Kim SS, and Lee JH, Scripta Materialia 1999; $41: 767$. https://doi.org/10.1016/S1359-6462(99)00215-8

[17] Hassas-irani SB, Zarei-hanzaki A, Bazaz B, and Roostaei AA, Materials \& Design 2013; 46: 579. https://doi.org/10.1016/j.matdes.2012.10.041

[18] Chitra S, Ojha SN, and Singh JK, International Journal of Emerging Trends in Science \& Technology 2016; 3: 159.

[19] [19] Haghdadi N and Abedi HR, Materials \& Design 2013; 49: 878.

https://doi.org/10.1016/j.matdes.2013.02.051

[20] Emamy $M$, Razaghian $A$ and Karshenas $M$, Materials \& Design 2013; 46: 824.

https://doi.org/10.1016/j.matdes.2012.10.060

[21] Peng JH, Xiao LT, Jian THE and De YXU, Transactions of Non-ferrous Metal Society of China 2014; 21: 1950. https://doi.org/10.1016/S1003-6326(11)60955-2

[22] Ahmad S, Abdollah ZA, Soleymani S, Saeid T and Assadi H, Materials Charact erization 2011; 63: 90. 